\title{
Optimized Design of Bi-Directional Dual Active Bridge Converter for Low-Voltage Battery Charger
}

\author{
Dong-Keun Jeong ${ }^{*, * *}$, Myung-Hyo Ryu ${ }^{* *}$, Heung-Geun Kim ${ }^{* * *}$, and Hee-Je Kim ${ }^{\dagger}$ \\ ${ }^{*}$ Department of Electrical Engineering, Pusan National University, Pusan, Korea \\ ${ }^{* *}$ Power Conversion and Control Research Center, HVDC Research Division, KERI, Changwon, Korea \\ ${ }^{* * *}$ Department of Electrical Engineering, Kyungpook National University, Daegu, Korea
}

\begin{abstract}
This study proposes an optimized design of a dual active bridge converter for a low-voltage charger in a military uninterrupted power supply (UPS) system. The dual active bridge converter is among various bi-directional DC/DC converters that possess a high-efficiency isolated bi-directional converter. In the general design, the zero-voltage switching(ZVS) region is reduced when the battery voltage is high. By contrast, efficiency is low because of high conduction losses when the battery voltage is low. Variable switching frequency is applied to increase the ZVS region and the power conversion efficiency, depending on battery voltage changes. At the same duty, the same power is obtained regardless of the battery voltage using the variable switching frequency. The proposed method is applied to a $5 \mathrm{~kW}$ prototype dual active bridge converter, and the experimental results are analyzed and verified.
\end{abstract}

Key words: Bi-directional control algorithm, Dual active bridge (DAB) converter, Soft switching (ZVS), Variable switching frequency

\section{INTRODUCTION}

The demand for electric power supply systems for electronics and telecommunications has recently increased. Electric power supply systems generally have numerous requirements in terms of efficiency, size, and cost. Reliability is also an important element of electric power supply systems. In particular, the power systems used in hospitals, Internet data centers, and the military require extremely high power quality and system reliability. The occurrence of power failure in these systems results in serious overall system losses. To avoid power supply interruptions, these power systems contain an uninterrupted power supply (UPS). A UPS system is typically used to protect electrical hardware from expected power disruptions. This system can provide high-quality power without transmission interruption to the load, even when the voltage source has voltage sags or power outage.

Any disruption in electric supply at any time will incur tremendous damage to the security of military equipment.

Manuscript received Dec. 5, 2013; accepted Mar. 1, 2014

Recommended for publication by Associate Editor Woo-Jin Choi.

'Corresponding Author: heeje@pusan.ac.kr

Tel: +82-51-510-2770, Mobile: +82-10-2295-0613, Pusan Nat'l Univ.

*Dept. of Electrical Eng., Pusan National University, Korea

*** Power Conversion and Control Research Center, HVDC Research

Division, KERI, Korea

${ }^{* * *}$ Department of Electrical Eng., Kyungpook National University, Korea

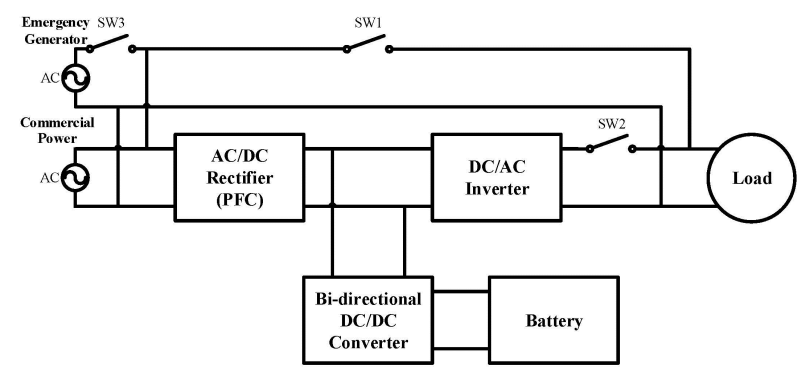

Fig. 1. Military UPS System.

Therefore, such equipment requires a UPS system. As shown in Fig. 1, the general military UPS system applied in this paper is composed of an $\mathrm{AC} / \mathrm{DC}$ rectifier, bi-directional $\mathrm{DC} / \mathrm{DC}$ converter, battery, and $\mathrm{DC} / \mathrm{AC}$ inverter. A bi-directional $\mathrm{DC} / \mathrm{DC}$ converter is necessary in a UPS system to charge and discharge the battery.

An isolated low-voltage battery charger requires wide input and output voltage, high efficiency, comprehensive load-range operation, and simple circuit topology. Various bidirectional isolated DC-DC converters have been proposed as interfaces for energy storage devices with a focus on UPS systems.

A boost full-bridge zero-voltage switching (ZVS) PWM DC/DC converter was developed for bi-directional high-power applications. This topology is suitable for bi-directional power conversion because it boosts operation for low-to-high voltage 
power conversions and a buck operation for high-to-low voltage conversions. However, this topology requires additional snubber circuits to restrain the voltage stress of the switches, which increases circuit complexity and decreases power conversion efficiency [1], [2]. A bi-directional phase-shift full-bridge converter was suggested with high-frequency galvanic isolation for energy storage systems [3], [4]. This converter improves power conversion efficiency by using a soft-switching feature. However, this converter requires input voltage variations to regulate the constant output voltage because the topology can only realize a step-down operation. A bi-directional full-bridge CLLC resonant converter was introduced without any snubber circuits. This topology can operate under the soft-switching conditions of the primary side switches and the secondary side rectifier. In addition, the topology confines the input and output voltage stresses without any clamp circuits [5]. However, a wide range voltage control is difficult to achieve because of resonant characteristics. In addition, the high voltage gain at light loads is difficult to control.

Dual active bridge (DAB) converters have been widely used because they operate with high performance, high efficiency, galvanic isolation, and an inherent soft-switching feature [6]. Bi-directional power transmission is a characteristic of the $\mathrm{DAB}$ converter that enables flexible interfacing with energy storage devices [7], [8]. DAB converters are suitable for bi-directional DC/DC converters using low-voltage battery chargers. However, despite having an inherent soft-switching characteristic, DAB converters are limited to a reduced operating range that depends on the voltage conversion ratio and output current. A problem in the ZVS region is encountered when a DAB converter is applied to a UPS system. If a DAB converter charges or discharges the battery in the UPS system, the battery voltage changes. In the general design, the required duty, which is a high battery voltage, is smaller than that when the battery voltage is low to achieve the same power. The ZVS region is reduced when the necessary duty is minimal. In addition, the peak current of leakage inductor and the rms current are increased at a low battery voltage. The power conversion efficiency is thus decreased.

In this paper, leakage inductance is designed for the use of wide duty to overcome the vulnerability mentioned above. For this reason, the ZVS region is expanded near the high battery voltage. In addition, if the battery voltage is changed, the switching frequency becomes variable relative to the battery voltage changes. Regardless of the battery voltage, fixed duty is used at the same load. Efficiency is increased near the low battery voltage by reducing the used duty and frequency. An experiment was performed to verify the performance of the proposed methods using a $5 \mathrm{~kW}$ prototype dual active bridge converter.

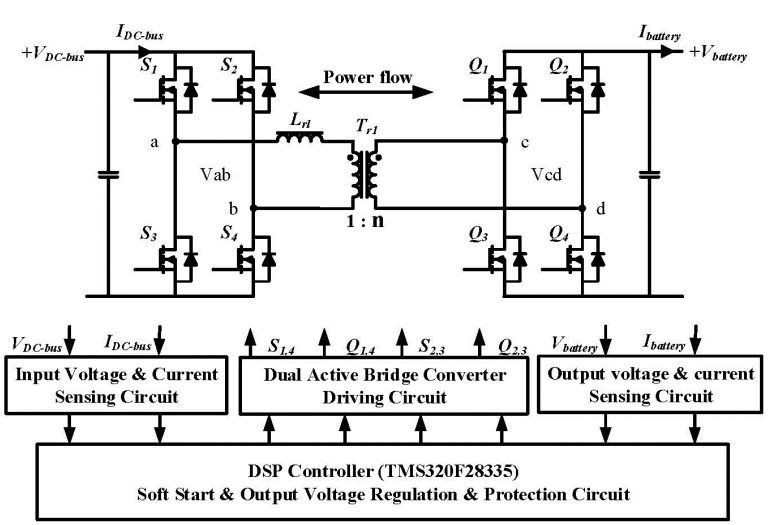

Fig. 2. Circuit configuration of the proposed dual active bridge converter

This paper is organized as follows: A DAB DC/DC converter, including the ZVS condition, is reviewed in Section II. The proposed methodology using the variable switching frequency is presented in Section III. The control algorithm of the proposed method is presented in Section IV, whereas the experimental results are illustrated in Section $\mathrm{V}$. The conclusions are given in Section VI.

\section{DUAL ACTIVE BRIDGE DC/DC CONVERTER}

A DAB converter consists of two full-bridge circuits, which are joined by an isolated transformer and a leakage inductor $\mathrm{L}_{\mathrm{r}}$, as shown in Fig. 2. The full bridge on the left side is connected to the DC-bus, and the full bridge on the right side is attached to the battery. Each bridge is controlled to provide a DC-bus square wave voltage. The two square waves can be suitably phase shifted with respect to each other to control the power flow from one DC source to another. In buck mode, when the phase of the $V_{c d}$ square wave is shifted by the $V_{a b}$ square wave, $n V_{\text {DC-bus }}+V_{\text {battery, }} \quad n V_{\text {DC-bus }}-V_{\text {battery, }}$ and $-n V_{\text {DC-bus }}-V_{\text {battery }}$ are represented in the leakage inductor. Current flows through leakage inductance because of the voltage difference. In contrast to the buck mode, the phase of the $\mathrm{V}_{\mathrm{ab}}$ square wave is shifted by the phase of the $\mathrm{V}_{\mathrm{cd}}$ square wave. Thus, bidirectional power flow is enabled through the transformer and inductor, and power flows through the bridge, thus generating the leading square wave [4], [9].

The average currents, peak, and rms currents of the leakage inductor are derived based on the linear waveform for $I_{L}$. The difference in voltage between the two bridges appears across the coupling inductor, and the inductor current changes with a constant slope, as shown in Fig. 3. Expressions for inductor current are derived for switching instants $\mathrm{I}_{\mathrm{L} 2}$ and $\mathrm{I}_{\mathrm{L} 1}$ in boost mode. The current at the DC-bus side switching instant is expressed as follows:

$$
I_{L 2}=\frac{T_{S}\left[n V_{D C-\text { bus }}+V_{\text {battery }}(2 d-1)\right]}{4 L}
$$


where $n$ is the transformer turn ratio. Solving for the battery switching instant current based on the current slope during the interval $\mathrm{dT}_{\mathrm{s}} / 2$ yields

$$
I_{L 1}=\frac{T_{S}\left[V_{\text {battery }}+n V_{D C-\text { bus }}(2 d-1)\right]}{4 L}
$$

The waveform is periodic over half a cycle. Thus, dividing the area by the duration, that is, $\mathrm{T}_{\mathrm{s}} / 2$, yields the average output current of the DAB converter. From (1) and (2), we solve $\mathrm{I}_{\text {battery }}$ as

$$
I_{\text {battery }}=\frac{n V_{D C-\text { bus }} T_{s}\left(d-d^{2}\right)}{2 L}
$$

The leakage inductor stores energy to ensure the charge or discharge of the switch output capacitances at the switching instants for the soft-switching operation because resonance occurs among switches, output capacitance, and leakage inductance while the switches are turned off. The body diode conducts when the switch is turned on, and the current that flows through the switches is positive during turn-off switching. The current at the battery side switching instant must be greater than zero when applying ZVS conditions to the inductor current waveforms to achieve the ZVS in the battery side bridge, as shown in Fig. 3. Thus, the following condition must be satisfied for the ZVS operation in the battery side on (4):

$$
I_{L 1}=\frac{T_{s}\left[n V_{D C-\text { bus }}(2 d-1)+V_{\text {battery }}\right]}{4 L} \geq 0
$$

Given that an increased energy must be stored in the leakage inductance to achieve soft switching (ZVS), the expression for the minimum inductor current is obtained as follows [10-12]:

$$
I_{L}=2 \sqrt{\frac{\left(V_{\text {battery }} / n\right) V_{D C-\text { bus }}}{\left(L / n^{2}\right) / C_{s}}}
$$

From (5), the output capacitance is given by

$$
I_{L 1}=\frac{T_{s}\left[n V_{D C-\text { bus }}(2 d-1)+V_{\text {battery }}\right]}{4 L} \geq 2 \sqrt{\frac{\left(V_{\text {battery }} / n\right) V_{D C-\text { bus }}}{\left(L / n^{2}\right) / C_{s}}}(6)
$$

With the solution for (6), the duty ratio in ZVS operation for $V_{\text {battery }} / n V_{D C \text {-bus }}<1$ is given by

$$
d \geq 0.5-\frac{V_{\text {battery }}}{2 n V_{D C-b u s}}+\frac{4}{T_{s}} \sqrt{\frac{\left(V_{\text {battery }} / n\right)\left(L / n^{2}\right) C_{s}}{V_{D C-b u s}}}
$$

\section{PROPOSED METHODOLOGY}

Battery output voltage is variable while the battery is charged and discharged. Fig. 4 indicates the discharge characteristic of the battery cell. The battery applied to the proposed UPS system consists of seven battery cells with $4 \mathrm{~V}$ connected in series and two pairs of the seven cells connected in parallel. From Fig. 4, the maximum discharge voltage of the battery is $28 \mathrm{~V}$. The maximum voltage of the battery is $\mathrm{V}_{\text {battery.max }}(28 \mathrm{~V})$, and $\mathrm{V}_{\text {battery.min }}(20 \mathrm{~V})$ is the minimum voltage.

The emergency generator operation in the UPS system consumes a minimum of $2 \mathrm{~min}$ and a maximum $30 \mathrm{~min}$. The

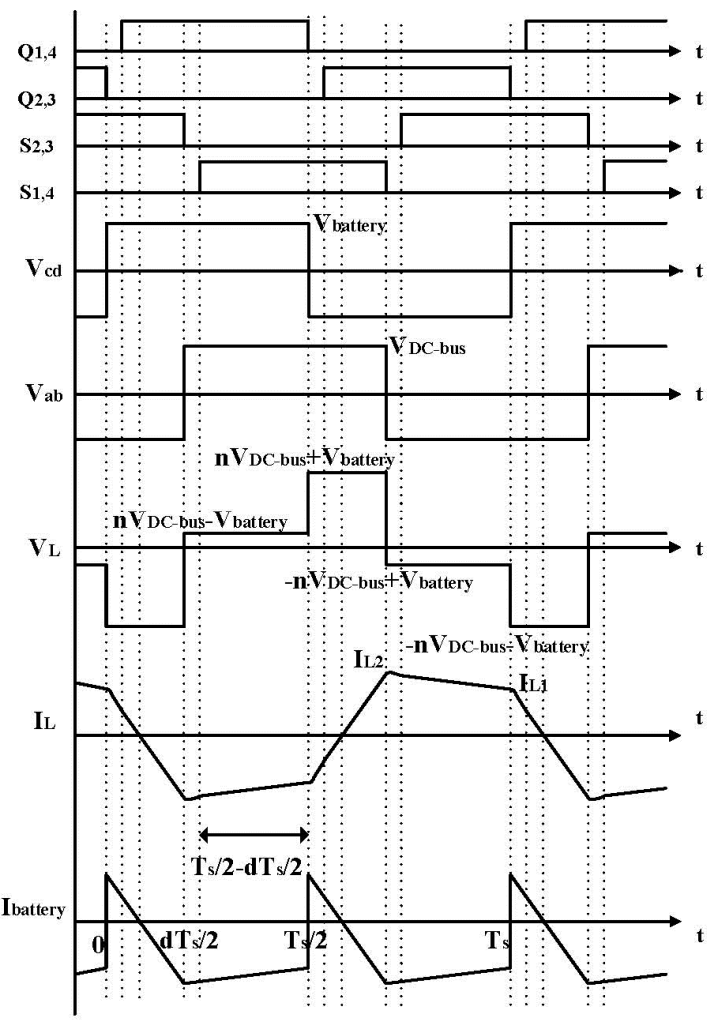

Fig. 3. Operating waveforms of the DAB converter during boost mode.

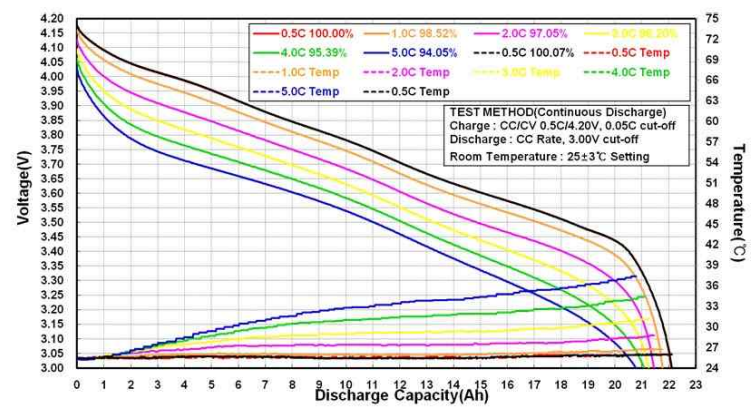

Fig. 4. Discharge characteristic of the end-cell applied UPS system.

emergency generator operates before falling to $V_{\text {batterymin }}$ for the majority of cases. Therefore, a DAB converter is designed based on $\mathrm{V}_{\text {battery.max }}$.

\section{A. General Design of the DAB Converter}

The theoretical maximum duty of the DAB converter is 0.5 according to (8). If the DAB converter is used for fixed input and output voltages, the full load is designed to operate at the maximum duty to utilize the widest ZVS range. The used maximum duty is designed as 0.45 given the overload and transient responses.

$$
P_{\text {battery }}=\frac{n V_{D C-\text { bus }} V_{\text {battery }} T_{s}\left(d-d^{2}\right)}{2 L}
$$




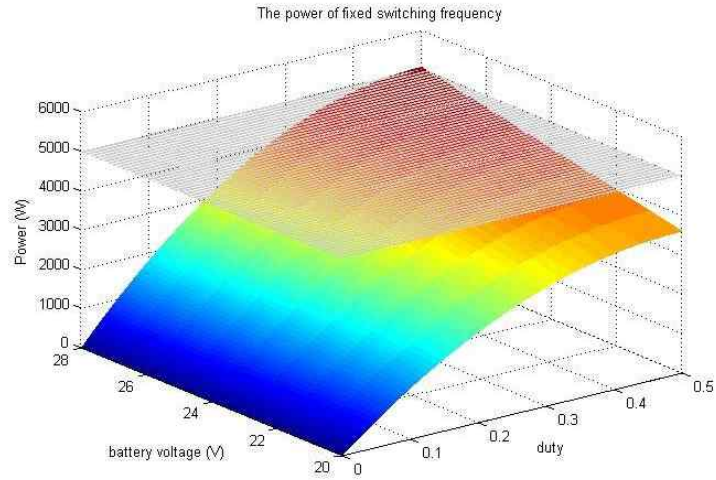

(a)

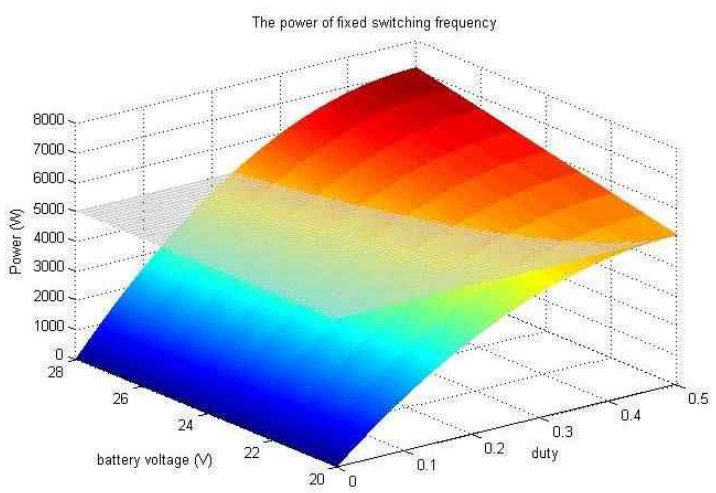

(b)

Fig. 5. Power relation between output voltage and duty in a general fixed switching frequency (a) the designed 0.45 duty at $\mathrm{V}_{\text {battery.max }}$, (b) the designed 0.45 duty at $\mathrm{V}_{\text {battery.min. }}$

However, when the output voltage of battery decreases to $\mathrm{V}_{\text {batterymin, }}$, the system cannot be operated at full load because of an insufficient of gain resulting from the variable battery voltage from (8), as shown in Fig. 5 (a). The designed maximum duty must be less than 0.45 to operate smoothly at full load once the battery voltage is variable from $V_{\text {battery.min }}$ to $\mathrm{V}_{\text {battery.max }}$.

Fig. 5 (b) indicates that the required duty is smaller than the duty at $\mathrm{V}_{\text {batterymin }}$ from (8). When the battery voltage is $V_{\text {battery.max }}$, the duty is $d_{1}$, whereas the duty is $d_{2}$ at $V_{\text {battery.min. }}$.

$$
d_{1}=\frac{1}{2}-\frac{1}{2} \sqrt{\frac{4 V_{\text {battery.min }} d_{2}^{2}-4 V_{\text {battery.min }} d_{2}+V_{\text {battery.max }}}{V_{\text {battery.max }}}}
$$

The required $d_{1}$ can be achieved from (9). The maximum duty should be designed to be less than duty $\mathrm{d}_{1}$ at full load to operate at full load with $\mathrm{V}_{\text {battery.min. At }} \mathrm{V}_{\text {battery.max }}$, lower duty of 0.229 is required at the full load, as shown in Fig. 5 (b). The maximum duty 0.45 is used for the full load at $V_{\text {battery.min. }}$ However, the DAB converter cannot be operated under this condition. However, if the used duty is as small as $\mathrm{V}_{\text {batterymax }}$, the ZVS region is decreased from (7). Switching loss and noise easily occurs in a narrow ZVS region, and controller configuration becomes difficult to assess.

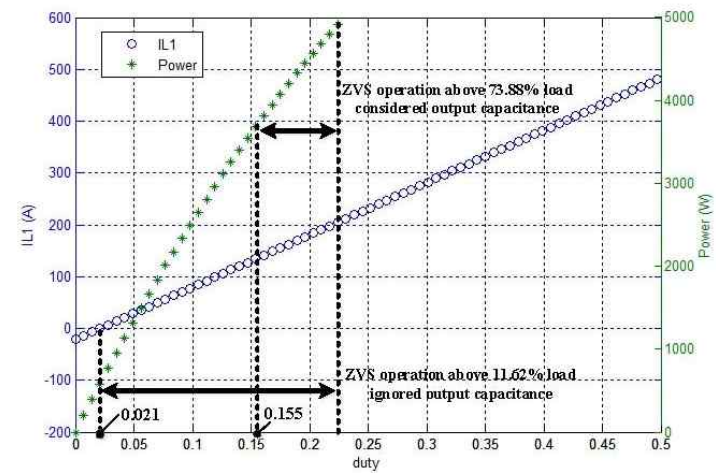

(a)

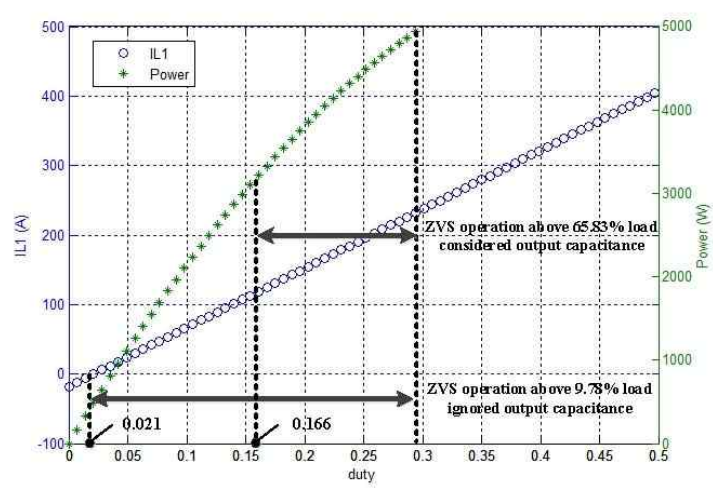

(b)

Fig. 6. The ZVS region (a) fixed switching frequency, $\mathrm{L}_{\mathrm{rll}}=$ $34.853 \mu \mathrm{H}, \mathrm{V}_{\text {battery }}=28 \mathrm{~V}, \mathrm{f}_{\mathrm{s}}=70 \mathrm{kHz},(\mathrm{b})$ applied variable switching frequency, $\mathrm{L}_{\mathrm{r} 12}=41.454 \mu \mathrm{H}, \mathrm{V}_{\text {battery }}=28 \mathrm{~V}, \mathrm{f}_{\mathrm{s}}=70 \mathrm{kHz}$

By contrast, if the used duty is the maximum duty at full

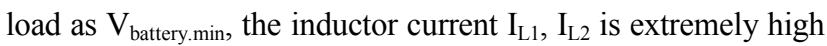
although the ZVS region is increased. When the inductor current is $\mathrm{I}_{\mathrm{L} 2}$, the primary switches of $\mathrm{DAB}$ converter are turned off, whereas the secondary switches are turned off at $\mathrm{I}_{\mathrm{L} 1}$. Thus, switching loss is increased in the high-current DAB converter. In addition, the rms current and conduction loss are increased.

\section{B. Proposed Design of the DAB Converter}

The following method is proposed to solve these weaknesses. The maximum duty of the DAB converter, which is 0.3 , is used to obtain the increased ZVS region at $\mathrm{V}_{\text {battery.max }}$ and to achieve high efficiency at $\mathrm{V}_{\text {battery.min }}$. The necessary leakage inductance can be obtained from (3). The primary leakage inductance $\mathrm{L}_{\mathrm{rl}}$ is designed as 0.229 duty under $\mathrm{V}_{\text {battery.max }}$, with $\mathrm{L}_{\mathrm{rl1}}$ as 34.853 $\mu \mathrm{H}$. The primary leakage inductance $\mathrm{L}_{\mathrm{r} 12}$ is optimally designed as 0.3 duty at $\mathrm{V}_{\text {batterymax }}$ condition, with $\mathrm{L}_{\mathrm{r} 12}$ as $41.454 \mu \mathrm{H}$. The primary leakage inductance is changed from $\mathrm{L}_{\mathrm{r} l 1}$ to $\mathrm{L}_{\mathrm{r} 12}$.

The ZVS region of the designed $\mathrm{L}_{\mathrm{r} 2}$ is increased to $8.05 \%$ wider than that obtained with $\mathrm{L}_{\mathrm{rl} 11}$ at $\mathrm{V}_{\text {batterymax }}$ by increasing the leakage inductance in (4), (7), and (8), as shown in Fig. 6. The output capacitance must be considered in calculating the ZVS region because the five switches of secondary side are 


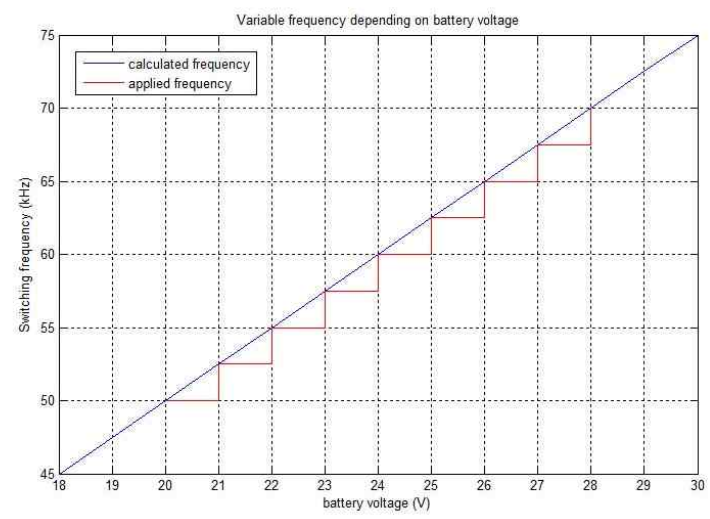

Fig. 7. Calculated and applied switching frequency depending on battery voltage.

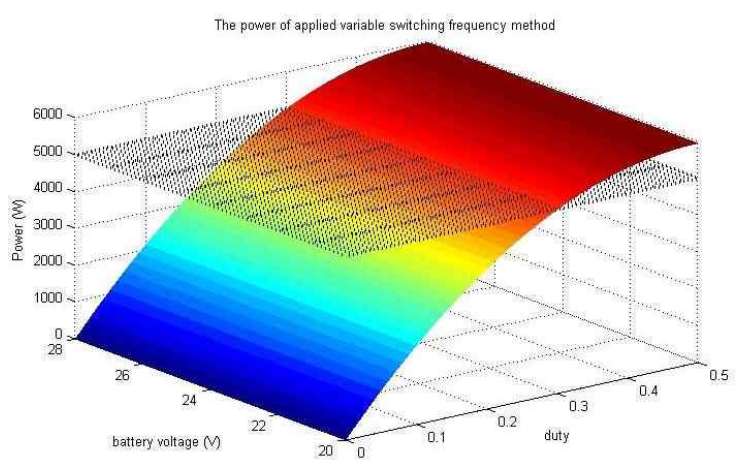

Fig. 8. Power relation between the output voltage and duty in applied variable switching frequency.

connected in parallel.

In addition, a variable switching frequency method based on battery voltage is proposed. The proposed 0.3 duty cannot operate at full load at a fixed switching frequency. However, if variable switching frequency is applied, the proposed duty can operate at full load regardless of battery voltage. When the battery voltage is decreased through discharge, the switching frequency is reduced. Thereafter, the switching, transformer, and inductor losses are decreased. When the battery voltage is $\mathrm{V}_{\text {battery.max }}$, the frequency is $\mathrm{f}_{\mathrm{s} \text {.max }}$. Conversely, the frequency is $f_{\text {s.min }}$ at $V_{\text {battery.min }}$. The $f_{\text {s.max }}$ for obtaining the same power from (8) depends on battery voltage can be derived as

$$
f_{s \text { max }}=\frac{V_{\text {battery.max }}}{V_{\text {battery.min }}} f_{\text {s.min }}
$$

From (10), the frequency for obtaining the same power when the battery voltage decreases from $\mathrm{V}_{\text {batterymax }}$ to $\mathrm{V}_{\text {batterymin }}$ is shown in Fig. 7. A step-by-step variation of the switching frequency is applied.

From (8), Variable switching frequency is applied to the DAB converter to obtain the same power relative to the battery voltage. Fig. 8 shows that similar duty results in the same power regardless of the battery voltage. At $\mathrm{V}_{\text {battery.min, }}$ the design of the fixed switching frequency requires the

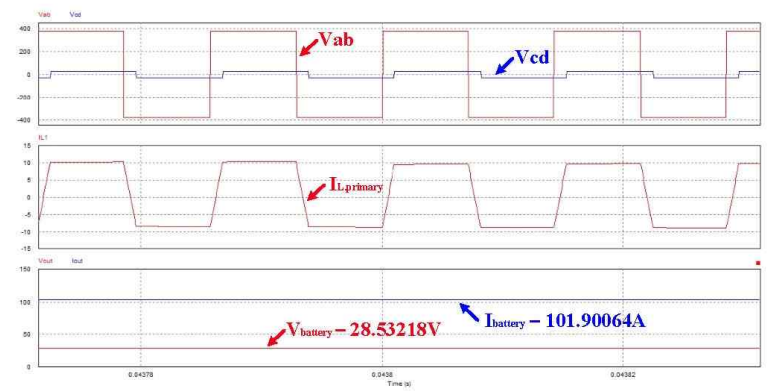

Fig. 9. DAB converter simulation for operation at $2.8 \mathrm{~kW}$ during buck mode.

maximum duty at the full load, as shown in Fig. 5 (b), and the design of the applied variable switching frequency requires the fixed 0.3 duty at the full load, as shown in Fig. 8 .

In the conventional design, inductor currents $\mathrm{I}_{\mathrm{L} 1}$ and $\mathrm{I}_{\mathrm{L} 2}$ of the secondary side and the rms current are significantly increased when the battery voltage is low. This feature is the main cause of the low power conversion efficiency and the high thermal design cost. The inductor current $\mathrm{I}_{\mathrm{L} 1}$ and the secondary side current $\mathrm{I}_{\mathrm{L} 2}$ of the transformer can be reduced by the proposed design method. Therefore, the number of switch components connected in parallel can be reduced, and the structure of the heat sink can be simplified. These characteristics are the advantages of the proposed design method.

\section{Simulation Results}

The $\mathrm{V}_{\mathrm{cd}}$ phase is shifted by the $\mathrm{V}_{\mathrm{ab}}$ phase in the buck mode, as shown in Fig. 9. $\mathrm{I}_{\mathrm{L}}$ is the inductor current of the transformer primary side and is a combination of the inductor current and the circulation current value. The controller is used to maintain a constant voltage with limited current. The control algorithm in Fig. 13 is verified through simulation. The battery voltage is controlled at $28 \mathrm{~V}$, and the battery charging current is limited to $100 \mathrm{~A}$.

In contrast to buck mode, the phase of the $\mathrm{V}_{\text {cd }}$ square wave is shifted by the $\mathrm{V}_{\mathrm{ab}}$ square wave in the boost mode, as shown in Fig. 10. The switching frequency is generally fixed to $f_{s}=$ $70 \mathrm{kHz}$. The simulation of the DAB converter at maximum power captures the operating point with $d=0.229$ and a battery voltage of $\mathrm{V}_{\text {battery }}=28 \mathrm{~V}$, as presented in Fig. 10(a). Fig. 10(b) shows the simulation with a battery voltage of 20 $\mathrm{V}$ at full load. At this battery voltage, the required duty is 0.45 at $5 \mathrm{~kW}$ load. The leakage current $\mathrm{I}_{\mathrm{L} 1}, \mathrm{I}_{\mathrm{L} 2}$ is high when the duty is 0.45 .

The proposed variable switching frequency method verifies that less duty is required at the full load according to (9). The full load duty is equal to 0.3 with operating conditions of $\mathrm{V}_{\text {batterymin }}$ and $50 \mathrm{kHz}$ by applying the variable switching frequency method, as shown in Fig. 11 (b). When the used duty is 0.3 , the leakage current $\mathrm{I}_{\mathrm{L} 1}, \mathrm{I}_{\mathrm{L} 2}$ is lower than that when using 0.45 duty, as shown in Fig. 10(b). The simulation verified that the same duty obtains the same power, 


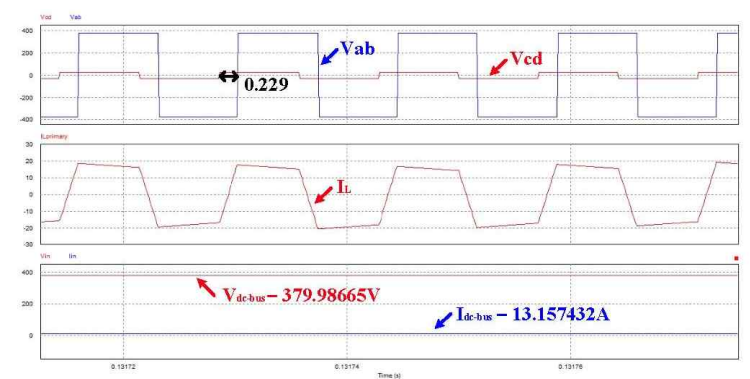

(a)

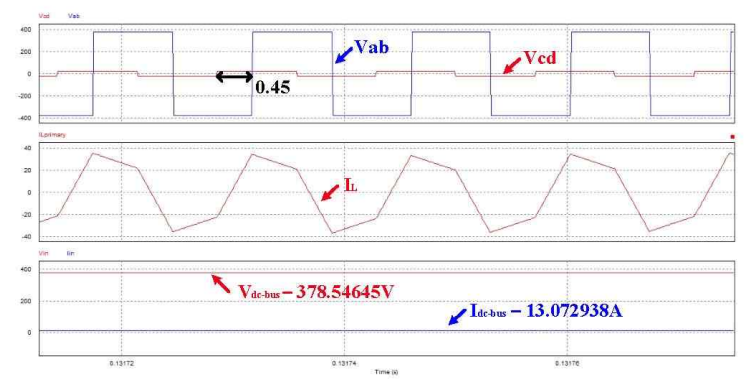

(b)

Fig. 10. DAB converter simulation at $5 \mathrm{~kW}$ during the boost mode, with a leakage inductance $\mathrm{L}_{\mathrm{rl} 1}=34.853 \mu \mathrm{H}$ (a) $\mathrm{V}_{\text {battery }}=28 \mathrm{~V}, \mathrm{f}_{\mathrm{s}}=$ $70 \mathrm{kHz}(\mathrm{b}) \mathrm{V}_{\text {battery }}=20 \mathrm{~V}, \mathrm{f}_{\mathrm{s}}=70 \mathrm{kHz}$.

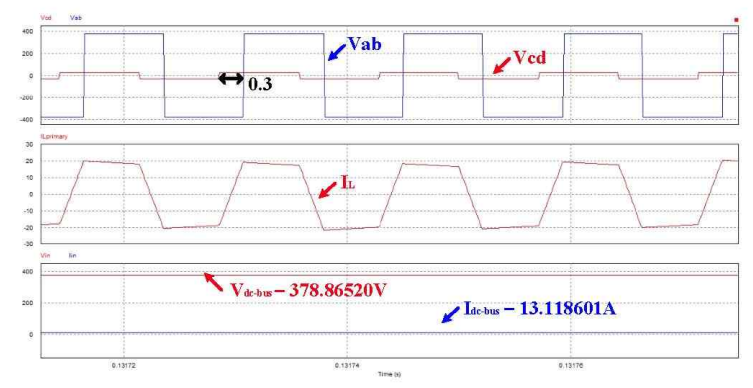

(a)

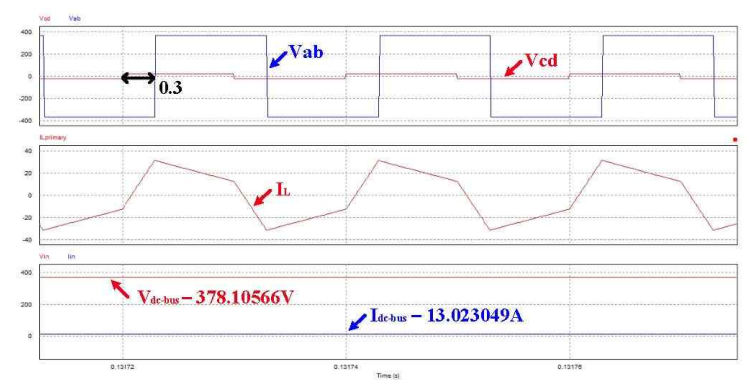

(b)

Fig. 11. Simulation of DAB converter at $5 \mathrm{~kW}$ during boost mode, leakage inductance $\mathrm{L}_{\mathrm{r} 12}=41.454 \mu \mathrm{H}$ (a) $\mathrm{V}_{\text {battery }}=28 \mathrm{~V}, \mathrm{f}_{\mathrm{s}}=70 \mathrm{kHz}$ (b) $\mathrm{V}_{\text {battery }}=20 \mathrm{~V}, \mathrm{f}_{\mathrm{s}}=50 \mathrm{kHz}$.

regardless of battery voltage.

\section{Proposed CONTROL Algorithm}

DSP (TMS320F28335) is used as the controller. Fig. 12 illustrates the DAB converter algorithm. The power stage is protected by blocking switching signals when overvoltage

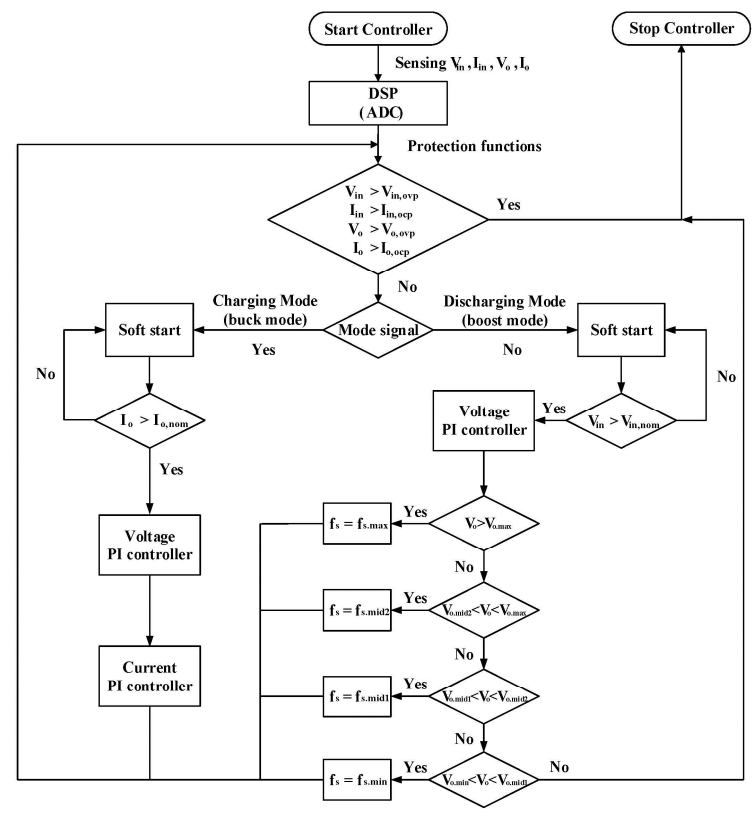

Fig. 12. DAB converter algorithm for low voltage charger.

and overcurrent are checked. ATS sends a mode signal for the selecting modes in the UPS system. If the ATS sends a high signal, the DAB converter operates in buck mode, in which the battery is charged by the $\mathrm{DAB}$ converter. If the ATS sends a low signal, the DAB converter operates in boost mode, and the battery is discharged by the DAB converter. Thus, the voltage of the battery changes over time. Frequency changes according to battery voltage. If the battery voltage is changed under $\mathrm{V}_{\text {battery.min, }}$ the controller is blocked to protect the power stage.

Phase shift control is adopted for the DAB converter to convert the high DC-bus voltage to low battery voltage or the low battery voltage to high DC-bus voltage. The control loop is shown in Fig. 13.

This phase shift determines the power transfer between the high DC-bus voltage and the low battery voltage [13]. The battery controller consists of a PI voltage controller and a PI current controller to limit the current in buck mode. This condition constantly controls battery voltage with limited currents, as shown in Fig. 13(a). The DC-bus voltage is controlled to maintain a constant voltage in boost mode, as shown in Fig. 13 (b). In addition, the algorithm of the variable switching frequency considers disturbance.

Experimental results demonstrate that the applied variable switching frequency indicates higher efficiency and ZVS region than the general design when the proposed method is applied.

\section{EXPERIMENTAL RESULTS}

A prototype of the DAB converter was used for the experiment, as shown in Fig. 14. The input source of the primary side of the DAB converter is the DC-bus in the UPS 


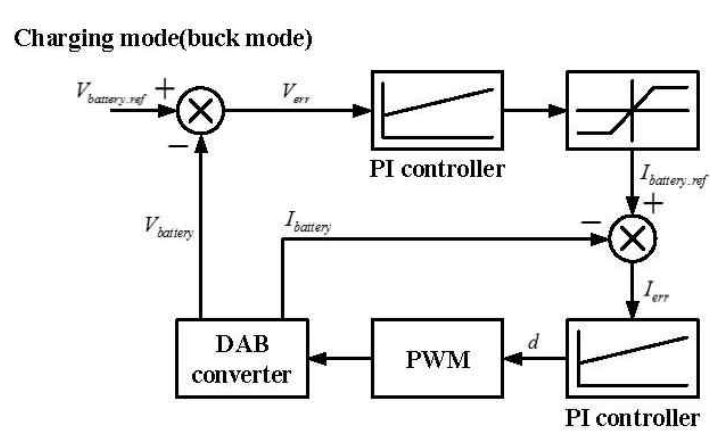

(a)

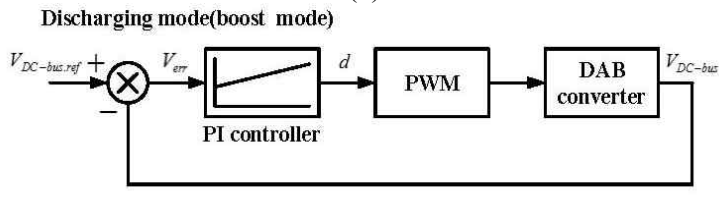

(b)

Fig. 13. The control diagram for the DAB converter. (a) Charging mode(buck mode). (b) Discharging mode(boost mode).

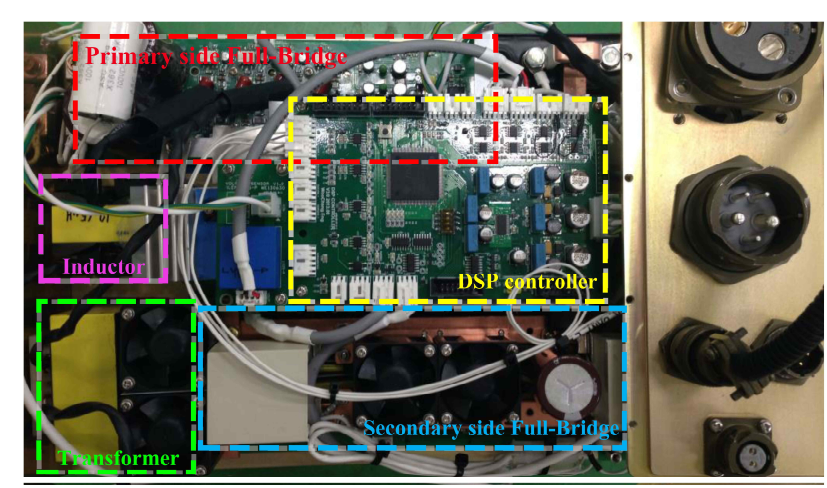

Fig. 14. Prototype of proposed DAB converter for a low voltage battery charger

TABLE I

Design SPECIFICATIONS OF A DAB ${ }^{1}$ CONVERTER

\begin{tabular}{c||c}
\hline \multicolumn{1}{c||}{ Input Voltage } & $380 \mathrm{~V}$ \\
\hline Output Voltage & $20 \sim 28 \mathrm{~V}$ \\
\hline Power & $5 \mathrm{~kW}$ \\
\hline Switching Frequency & $50 \mathrm{kHz} \sim 70 \mathrm{kHz}$ \\
\hline Primary leakage inductance & $41.454 \mu \mathrm{H}$ \\
\hline Transformer turn ratio & $1: 13$ \\
\hline Output Capacitors & $10000 \mathrm{uF}$ \\
\hline Input Capacitors & $1360 \mathrm{uF}$ \\
\hline
\end{tabular}

Dual Active Bridge

system. The used primary switches are 47N60CFD. Two parallel-connected switches are used to reduce conduction losses. The secondary side is connected to the battery. The used secondary side switches are IRFP4468 and are connected to five parallel switches to reduce conduction losses. Table 1 shows the design specifications of a DAB converter.
The DAB converter operates in buck mode when the phase of the $\mathrm{V}_{\mathrm{cd}}$ square wave is shifted by the $\mathrm{V}_{\mathrm{ab}}$ square wave, as shown in Fig. 15. Similar to the simulation, the experimental results verify that the battery voltage is controlled at $28 \mathrm{~V}$ by limiting the current to $100 \mathrm{~A}$ at $2.8 \mathrm{~kW}$ operation.

The ZVS condition necessitates that energy stored in the leakage inductor must be larger than the energy required to charge and discharge the output capacitance.

Secondary side switches cannot operate soft-switching at $3216 \mathrm{~W}$ load when the primary leakage inductance is $\mathrm{L}_{\mathrm{rll}}$, as shown in Fig. 16 (a). The reverse recovery occurs in the free-wheeling diodes during dead time. However, given the limited energy required to charge and discharge the output capacitance, $\mathrm{V}_{\text {battery }}$ occurs at the secondary side switches, as shown in Fig. 16(a). Fig. 16(b) verifies the ZVS boundary at $3727 \mathrm{~W}$ presented in Fig. 6(a). Leakage inductance is changed from $\mathrm{L}_{\mathrm{r} 11}$ to $\mathrm{L}_{\mathrm{r} 12}$.

Secondary side switches operate soft switching at $3216 \mathrm{~kW}$ load, as shown in Fig. 17. Similar to the results in Fig. 6, experimental results verified that the ZVS region is increased by $9.42 \%$. Fig. 6 indicates that the ZVS region increased by nearly $8.05 \%$ based on (7). The difference between (7) and the experimental results is caused by the turn ratio of the transformer. The calculated transformer turn ratio used in (7) is 13:1. However, the secondary wire consists of a copper strip to reduce the conduction losses of the secondary side. Thus, the transformer turn ratio is difficult to adjust accurately at 13:1. This ratio serves as the main cause of the difference between (7) and the experimental results.

The boost mode of the DAB converter operates at a fixed switching frequency of $70 \mathrm{kHz}$. $\mathrm{I}_{\mathrm{L} \text {.primary }}$ is the inductor current of the primary side of the transformer. Experimental results of the DAB converter at the maximum power capture the operating point with $d=0.229$ and a battery voltage of $\mathrm{V}_{\text {batterymax }}$ at full load, as shown in Fig. 18 (a). Fig. 18(b) shows the operation waveforms with a battery voltage of 20 $\mathrm{V}$ at the full load. Moreover, $20 \mathrm{~V}$ is the minimum battery voltage. Thus, the voltage across the leakage inductor is high. The slope of the inductor current is steep in the interval in which power is transferred. Therefore, in Fig. 18(b), the leakage currents $\mathrm{I}_{\mathrm{L} 1}$ and $\mathrm{I}_{\mathrm{L} 2}$ are higher than those of Fig. 18(a). The general design of the DAB converter was verified at $5 \mathrm{~kW}$, as shown in Fig. 18.

Fig. 19 shows the power of the $5 \mathrm{~kW}$ transfer at an applied variable switching frequency condition. Experimental results verify that 0.3 duty is required at a load of $5 \mathrm{~kW}$ at $\mathrm{V}_{\text {batterymax }}$, as shown in Fig. 19.

The DAB converter operates at a $5 \mathrm{~kW}$ load with the application of the variable switching frequency, as shown in Fig. 20. Switching frequency is $50 \mathrm{kHz}$ with a battery voltage of $20 \mathrm{~V}$. The required duty is 0.3 at the maximum power of 5 $\mathrm{kW}$. The leakage currents $\mathrm{I}_{\mathrm{L} 1}$ and $\mathrm{I}_{\mathrm{L} 2}$ and the rms current are lower in Fig. 20 than in Fig. 18(b). Similar to the simulation, 


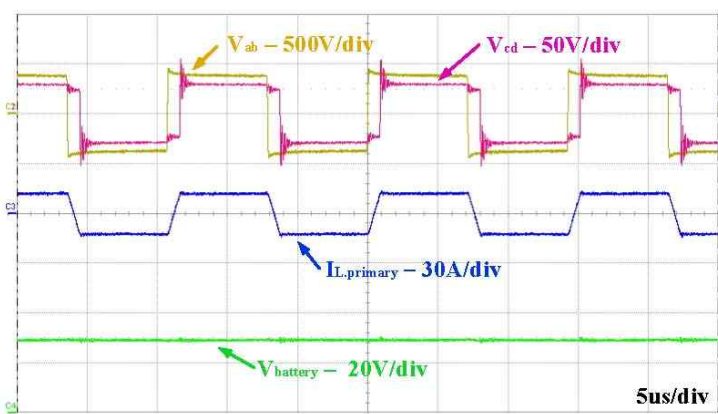

(a)

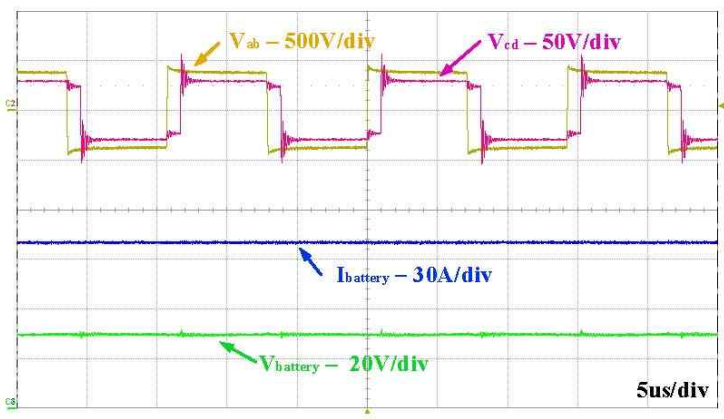

(b)

Fig. 15. Experimental results of the DAB converter at $2.8 \mathrm{~kW}$ during the buck mode, where $\mathrm{f}_{\mathrm{s}}=70 \mathrm{kHz}$, (a) operation waveforms, (b) the power of the charged battery.

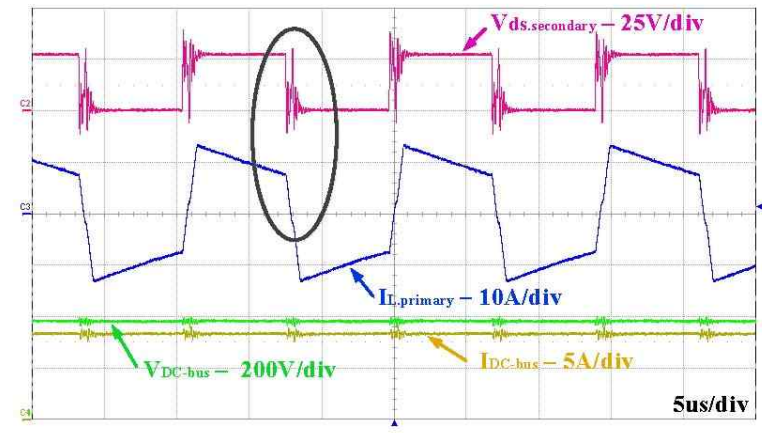

(a)

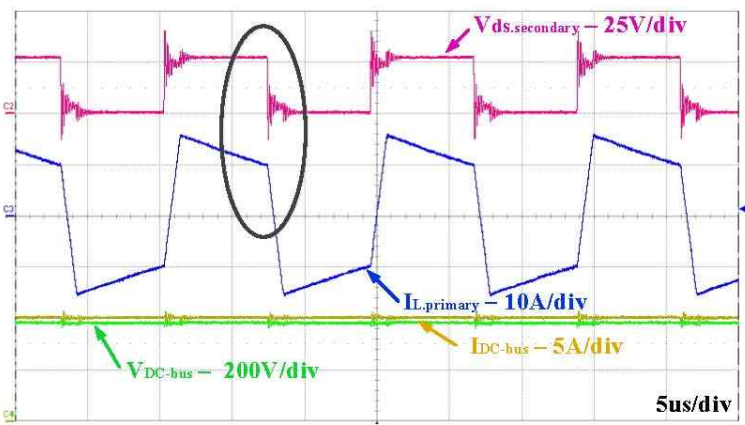

(b)

Fig. 16. Experimental results of ZVS region, $\mathrm{L}_{\mathrm{rl}}=34.853 \mu \mathrm{H}$, $\mathrm{V}_{\text {battery }}=28 \mathrm{~V}, \mathrm{f}_{\mathrm{s}}=70 \mathrm{kHz}$ (a) load $=3256 \mathrm{~W}(65.12 \%) \quad$ (b) load $=$ $3727 \mathrm{~W}(74.54 \%)$.

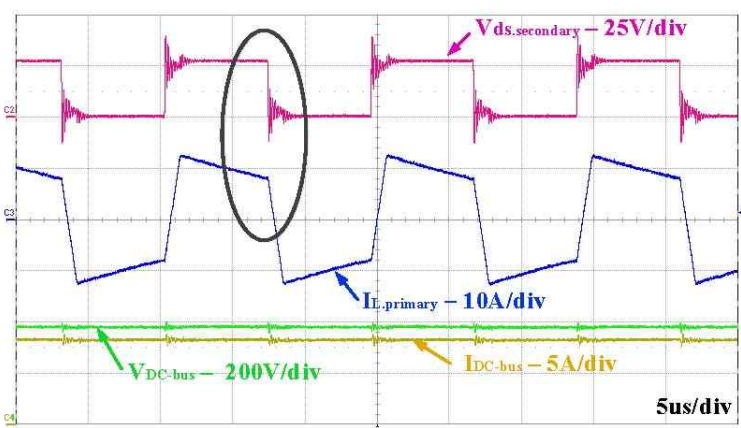

Fig. 17. Experimental results in the ZVS region, $\mathrm{L}_{\mathrm{rl} 2}=41.454 \mu \mathrm{H}$, $\mathrm{V}_{\text {battery }}=28 \mathrm{~V}, \mathrm{f}_{\mathrm{s}}=70 \mathrm{kHz}$, load $=3256 \mathrm{~W}(65.12 \%)$.

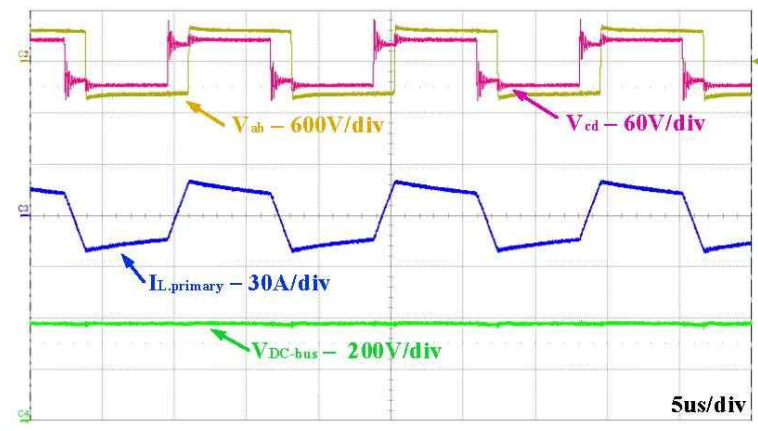

(a)

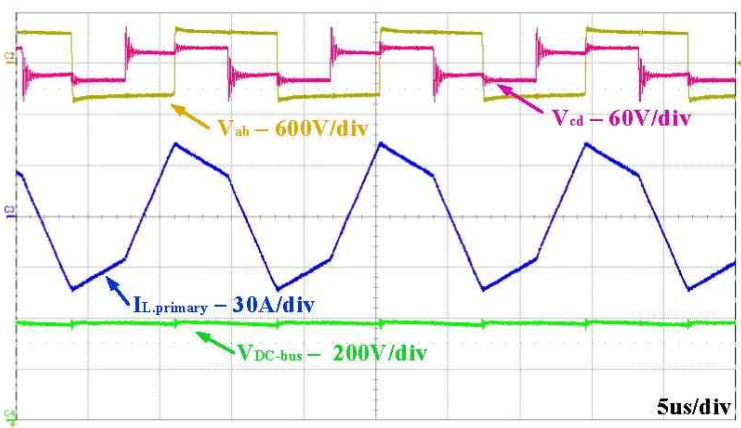

(b)

Fig. 18. Experimental results of DAB converter at $5 \mathrm{~kW}$ during boost mode, leakage inductance $\mathrm{L}_{\mathrm{rl} l}=34.853 \mu \mathrm{H}$ (a) $\mathrm{V}_{\text {battery }}=28 \mathrm{~V}$, $\mathrm{f}_{\mathrm{s}}=70 \mathrm{kHz}(\mathrm{b}) \mathrm{V}_{\text {battery }}=20 \mathrm{~V}, \mathrm{f}_{\mathrm{s}}=70 \mathrm{kHz}$.

the experimental results verified that the same power results from the same duty, regardless of the battery voltage, using the variable switching frequency.

Fig. 21 captures the efficiency according to battery voltage at a fixed $70 \mathrm{kHz}$ and $\mathrm{L}_{\mathrm{rl}}=34.853 \mu \mathrm{H}$. The used duty is large and the switching current is high when the battery voltage is low. Thus, the switching and conduction losses are increased.

Fig. 22 captures the efficiency according to the battery voltage at an applied variable switching frequency and at $\mathrm{L}_{\mathrm{r} 12}=$ $41.454 \mu \mathrm{H}$. The used duty is fixed at 0.3 regardless of the battery voltage. The switching frequency is reduced, and the $\mathrm{I}_{\mathrm{L} 1}$, $\mathrm{I}_{\mathrm{L} 2}$, and rms currents are decreased when the battery voltage is 


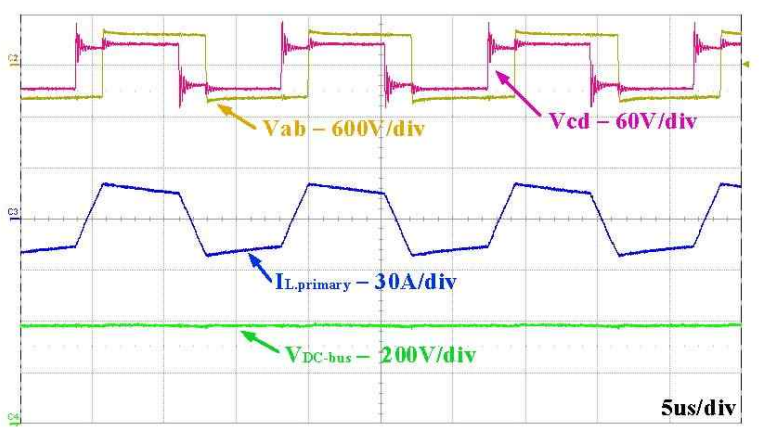

(a)

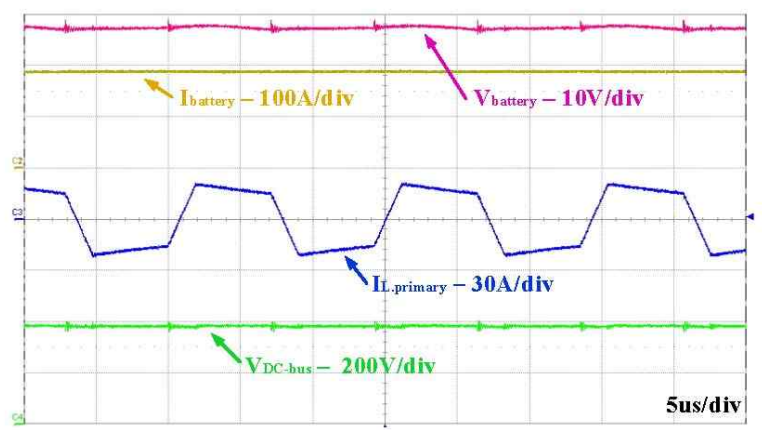

(b)

Fig. 19. Experimental results of the DAB converter at $5 \mathrm{~kW}$ during boost mode, leakage inductance $\mathrm{L}_{\mathrm{r} 22}=41.454 \mu \mathrm{H}, \mathrm{V}_{\text {battery }}=28 \mathrm{~V}, \mathrm{f}_{\mathrm{s}}$ $=70 \mathrm{kHz}$, (a) operation waveforms, (b) the power of the discharged battery.

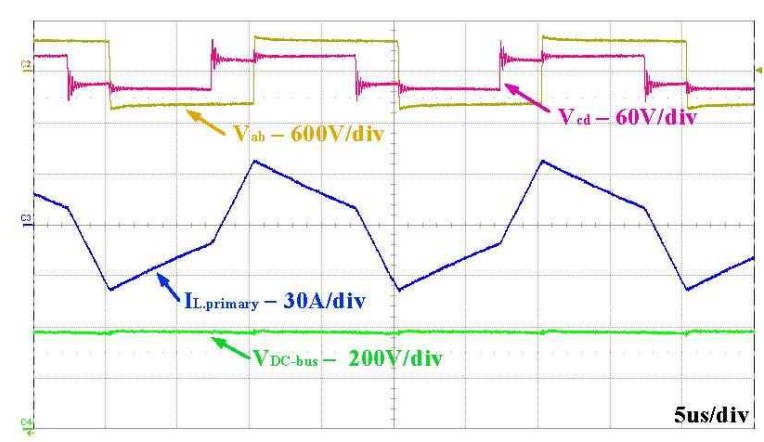

(a)

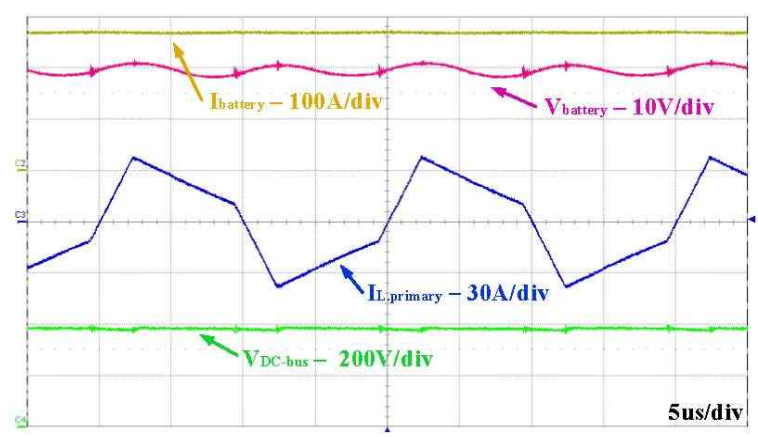

(b)

Fig. 20. Experimental results of the DAB converter at $5 \mathrm{~kW}$ during boost mode, leakage inductance $\mathrm{L}_{\mathrm{r} 12}=41.454 \mu \mathrm{H}, \mathrm{V}_{\text {battery }}=20 \mathrm{~V}, \mathrm{f}_{\mathrm{s}}$ $=50 \mathrm{kHz}$, (a) operation waveforms, (b) power of the discharged battery.

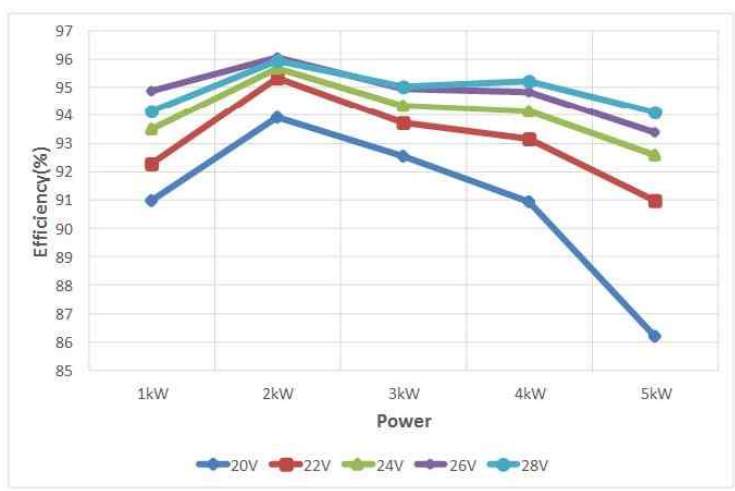

Fig. 21. Efficiency according to the battery voltage, $\mathrm{L}_{\mathrm{rl}}=$ $34.853 \mu \mathrm{H}, \mathrm{f}_{\mathrm{s}}=70 \mathrm{kHz}$.

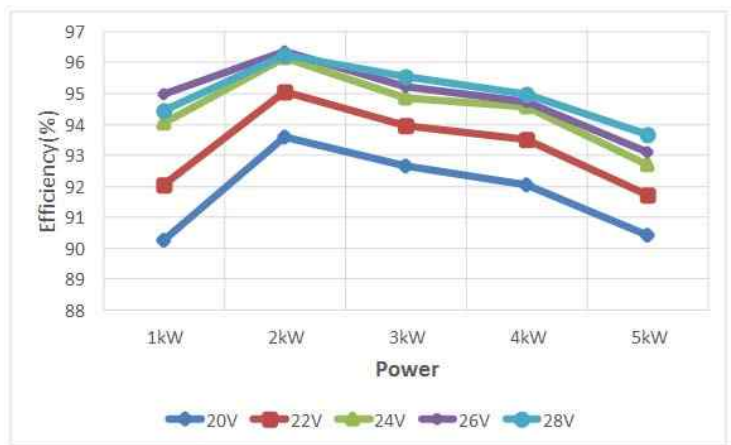

Fig. 22. Efficiency according to battery voltage, $\mathrm{L}_{\mathrm{r} 12}=41.454 \mu \mathrm{H}$, $\mathrm{f}_{\mathrm{s}}=50 \mathrm{kHz}$ to $70 \mathrm{kHz}$.

low. Thus, enhanced efficiency is observed in contrast to the fixed switching frequency. Experimental results verified that the power conversion efficiency is increased by $4 \%$ at the full load after comparing the general designs of the DAB converter.

\section{CONCLUSIONS}

This paper proposed the design and control method of a DAB converter for low-voltage chargers in a UPS system. The proposed method revealed that leakage inductance should be designed at 0.3 duty. In addition, the switching frequency varied depending on the battery voltage. The proposed method was applied to a $5 \mathrm{~kW}$ prototype $\mathrm{DAB}$ converter and was verified. The performance improved, and the ZVS region expanded by $9.42 \%$ near $V_{\text {batterymax }}$ through the proposed method. Furthermore, the power conversion efficiency was increased near $\mathrm{V}_{\text {battery.min. }}$.

\section{ACKNOWLEDGMENT}

This research was supported by the KERI Primary research program of MSIP/ISTK (No. 14-12-N0101-40). 


\section{REFERENCES}

[1] A. Mehdipour and S. Farhangi, "Comparison of three isolated bi-directional $\mathrm{dc} / \mathrm{dc}$ converter topologies for a backup photovoltaic application," in Proc. 2nd Int. Conf. Electric Power Energy Convers. Syst., pp.1-5, 2011.

[2] R.-J.Wai, C.-Y. Lin, and Y.-R. Chang, "High step-up bidirectional isolated converter with two input power sources," IEEE Trans. Ind. Electron., Vol. 56, No. 7, pp. 2629-2643, Jul. 2009.

[3] S. Inoue and H. Akagi, "A bidirectional dc-dc converter for an energy storage system with galvanic isolation," IEEE Trans. Power Electron., Vol. 22, No. 6, pp. 2299 2306, Nov. 2007.

[4] R. T. Naayagi, A. J. Forsyth, and R. Shuttleworth, "High-power bidirectional dc-dc converter for aerospace applications," IEEE Trans. Power Electron., Vol. 27, No. 11, pp. 4366-4379, Nov. 2012.

[5] H.-S. Kim, M.-H. Ryu, J.-W. Baek, and J.-H. Jung, "High-efficiency isolated bidirectional AC-DC converter for a DC distribution system," IEEE Trans. Power Electron., Vol. 28, No. 4, pp. 1642-1654, Apr. 2013.

[6] M. N. Kheraluwala, R. W. Gascoigne, D. M. Divan, and E. D. Baumann, "Performance characterization of a high-power dual active bridge DC-to-DC converter," IEEE Trans. Ind. Appl., Vol. 28, No. 6, pp. 1294-1301, Dec. 1992.

[7] S. Inoue and H. Akagi, "A bidirectional dc-dc converter for an energy storage system with galvanic isolation," IEEE Trans. Power Electron., Vol. 22, No. 6, pp. 2299-2306, Nov. 2007.

[8] N. M. L. Tan, S. Inoue, A. Kobayashi, and H. Akagi, "Voltage balancing of a 320-V, 12-F electric double-layer capacitor bank combined with a $10-\mathrm{kW}$ bidirectional isolated DC-DC converter," IEEE Trans. Power Electron., Vol. 23, No. 6, pp. 2755-2765, Nov. 2008.

[9] X. Li and A. K. S. Bhat, "Analysis and design of high-Frequency isolated dual-bridge series resonant DC/DC converter," IEEE Trans. Power Electron., Vol. 25, No. 4, pp. 850-862, Apr. 2010.

[10] M. N. Kheraluwala, R. W. Gascoigne, D. M. Divan, and E. D. Baumann, "Performance characterization of a high-power dual active bridge DC-to-DC converter," IEEE Trans. Ind. Appl., Vol. 28, No. 6, pp. 1294-1301, Dec. 1992.

[11] T. N. Ramasamy, "Bidirectional DC-DC converter for aircraft electric energy storage systems," Ph.D. Thesis, School Electr. Electron. Eng. Univ. Manchester, Manchester U.K., 2010.

[12] S. Inoue and H. Akagi, "A bidirectional DC-DC converter for an energy storage system with galvanic isolation," IEEE Trans. Power Electron., Vol. 22. No. 6, pp. 2299-2306, Nov. 2007.

[13] W. Friede, S. Rael, and B. Davat, "Mathematical model and characterization of the transient behavior of a PEM fuel cell," IEEE Trans. Power Electron., Vol. 19. No. 5, pp. 1234-1241, Sep. 2004.

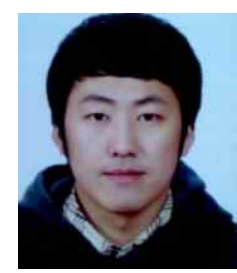

Dong-Keun Jeong was born in Pusan, Korea. He received his B.S. and M.S. degrees in Electrical Engineering from the Department of Interdisciplinary Program in Robotics of the Pusan National University, Jangjeondong, Geumjung-gu, Korea, in 2012 and 2014, respectively. He has been a researcher for the Power Conversion and Control Research Center, HVDC Research Division, Korea Electrotechnology Research Institute, Changwon, Korea since 2012. His research interests include $\mathrm{dc}-\mathrm{dc}$ converters, power converters for low-voltage DC distribution systems, high-efficiency AC-DC rectifier systems, and digitally controlled power electronics.

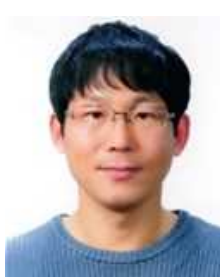

Myung-Hyo Ryu received his B.S. and M.S. degrees in Electrical Engineering from Kyungpook National University, Taegu, Korea, in 1997 and 1999, respectively. He was a Research Engineer for the SMPS Development Division, Samsung Electro-Mechanics Co. Ltd., Suwon, Korea from 2000 to 2002. He has been a senior researcher for the Power Conversion and Control Research Center, HVDC Research Division of the Korea Electrotechnology Research Institute in Changwon, Korea since 2002. His current research interests include LEDs drivers, power converters for low voltage DC distribution systems and high voltage DC transmission systems, and battery charger, including analysis, modeling, design, and control. Mr. Ryu is a member of the Korean Institute of Power Electronics.

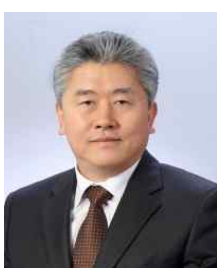

Heung-Geun Kim was born in Korea in 1956. He received his B.S., M.S., and Ph.D. degrees in Electrical Engineering from Seoul National University in 1980, 1982 and 1988, respectively. Since 1984, he has been with the Department of Electrical Engineering at Kyungpook National University, where he is currently a full professor and the director of the Microgrid Research Center. He was a Visiting Scholar at the Department of Electrical and Computer Engineering in the University of Wisconsin-Madison from 1990 to 1991, and at the Department of Electrical Engineering in the Michigan State University, USA from 2006 to 2007. His current research interests are ac machine control, PV power generation, and micro-grid system.

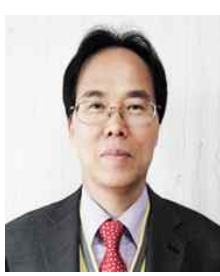

Hee-Je Kim received his B.S. and M.S. degrees in Electrical Engineering from Pusan National University, Korea in 1980 and 1982, respectively. He received his Ph.D. degree from Kyushu University in Hukuoka, Japan in 1990. He joined KERI in 1983, and went to Kyushu University to conduct research on laser systems and plasma applications. He has been a professor at the School of Electrical Engineering in the Pusan National University since 1995. His area of research includes laser and sensor applications, robotics, high voltage based power electronics, bio-medical applications, and renewable energy sources. 